\title{
CALENDAR ANOMALIES IN THE RUSSIAN STOCK MARKET: TRENDS OF THE RECENT DECADE
}

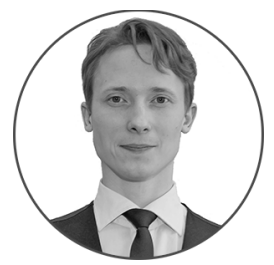

\section{Article history:}

Received 7 February 2018 Received in revised form 21 February 2018 Accepted 7 March 2018 Translated 30 May 2018 Available online 27 June 2018

JEL classification: G10, G14

Keywords: securities market, stock market, stock exchange, behavioral finance, Monday effect

\section{Danila V.VAL'KO}

South Ural Institute of Management and Economics, Chelyabinsk, Russian Federation valkodv@inueco.ru https://orcid.org/0000-0002-8058-7539

\begin{abstract}
Importance The article discusses calendar anomalies (behavioral effects) in the Russian stock market and the so called Day-of-the-week effect and Monday effect.

Objectives The research analyzes the Day-of-the-week effect and Monday effect, referring to 2007-2017 data of the Russian stock market and identifies behavioral differences between stock markets in Russia and economically developed countries.

Methods The research employs a set of systemic methods, such as structural-logical and factor analysis. I analyze empirical patterns using standard statistical methods.

Results Featuring abnormally low profitability on Wednesday, the Day-of-the-week effect also perseveres after the consolidation of trading platforms of the Moscow Exchange (MICEX) and Russian Trading System (RTS). In the mean time, although earlier studies captured the Friday effect, significantly high return has been recorded on Monday for the recent decade.

Conclusions and Relevance The Russian stock market resembles those ones of the most developed countries in terms of the Day-of-the-week effect and other behavioral characteristics. However, the domestic stock market is subject to ratchet effects that are observed in ties with other financial centers and economic cycles as a whole. This explains why Friday and Monday effects switch to Monday and Wednesday respectively.
\end{abstract}

๑) Publishing house FINANCE and CREDIT, 2018

The editor-in-charge of this article was Irina M. Vechkanova

Authorized translation by Irina M. Vechkanova

\section{Introduction}

Several recent decades have seen the Nobel Prize be awarded to scholars specializing in behavioral finance. These are H. Simon [1] (1978), R Selten [2] (1994) and D Kahneman [3] (2002). Their proceedings ignited researches into the way economic agents make decisions and stock markets behave. Notwithstanding the different nature of such studies (samples, markets, analyzable period), scholars recorded similar

${ }^{\dagger}$ For the source article, please refer to: Валько Д.В. Календарные аномалии на российском фондовом рынке: тенденции последнего десятилетия. Финансы и кредит. 2018. Т. 24. № 3. С. 550-562. URL: https://doi.org/10.24891/fc.24.3.550 phenomena, which failed to meet the hypothesis of effective market and contradicted the Capital Asset Pricing Model (CAPM), pricing model for non-current assets ${ }^{1}$.

Traced in the process of stand-alone observations of breaches in the rational economy principles or efficient market models, such phenomena can be conditionally qualified as anomalies. Nowadays a critical mass of such empirically proven observations of anomalies has

${ }^{1}$ Solodukhina A.V. [Behavioral capital asset pricing model]. Finansy $i$ kredit = Finance and Credit, 2010, no. 11, pp. 63-73. URL: https://cyberleninka.ru/article/v/povedencheskie-modelitsenoobrazovaniya-aktivov (In Russ.) 
converted into systemic constructs, which are classified or persuasively construed from perspectives of behavioral economics.

Influencing the behavior of prices and depending on repeating constituent of time, calendar anomalies were the first phenomenon that was discovered, i.e. monthof-the-year effect, day-of-the-week effect, year-end or year-beginning effect, holiday effect (after-holiday), etc. [4]. The Monday effect was one of the first phenomena that was discovered in all analyzable markets during certain periods under study, thus being the most interesting one. It was subsequently generalized to become the day-of-the-week effect.

The Monday effect causes a negative trend in a stock market, such as a stock index decline, drop in quotations of some companies' stocks at the beginning of a business week in comparison with other days. Basically it seldom demonstrates any direct relationship with the market closing. The effect is believed to have been discovered by M.J. Fields [5] (1931) and subsequently verified by F. Cross [6] (1973) and K. French [7] (1980), while studying weekly return on the U.S. companies' stocks for the period within 1953 to 1977.

Afterwards, in $1988 \mathrm{~J}$. Lakonishok and S. Smidt screened the 90-years data (1897-1987) for such an effect [8]. Like K. French, they found out that the return was much less than nil on Monday. Later on, analyzing the U.S. Standard \& Poors 500 (S\&P500) in 1977, A. Kamara [9] demonstrated that the stock index was still exposed to the Monday effect, albeit to a lesser extent. Furthermore, A. Kamara figured out that the effect had been gradually declining from 1962 up to 1993 with respect to portfolio of shares held by the U.S. mid caps.

It is not only the U.S. stock market where such calendar anomalies were found. In one of the recent researches into the identification of calendar anomalies, A. Agrawal and $\mathrm{K}$. Tandon conducted an ample analysis of stock markets in 19 countries [10], which totally accounted for 95 percent of total capitalization of stocks worldwide. The research verified the day-of-the-week effect in most of the developed markets. However, the effect is recorded on different days. The holiday effect is seen in the USA, United Kingdom, Canada, Germany, Italy, Brazil. The Tuesday effect is traced in Japan, France, Australia, Hong Kong, Belgium, Singapore, while the Friday effect is common almost for all the developed and emerging economies.

The day-of-the week effect was detected in the Russian stock market within the period from 1998 through 2007. However, the horizon of such researches is not enough to determine what circumstances and aspects make the market behave this way. There is some gap in empirical studies into this effect covering the period from 2007 up to the date.

This research is an attempt to analyze how the day-ofthe-week effect and Monday effect were developing in the Russian market for the period of 2007-2017, respectively identifying behavioral differences between the Russian stock market and those ones in economically advanced countries. Pursuing this objective, I scrutinize key studies into the effect on stock markets of developed economies and pay attention to the Russian one.

\section{Monday Effect in Stock Markets of Advanced Economies}

In 1987, J.F. Jaffe, R. Westerfield, C. Ma [11] released their research stating that untypically low return on Monday follows a stock market decline seen the previous week. Indeed, they observed the correlation of the Monday and Fridays effects. The first almost fades away provided that the market rose earlier (on Friday). To say it in other words, there is a positive correlation between return on Monday and return on Friday that preceded it. The research relied upon daily data on stock exchange indices of some advanced countries, such as S\&P 500 (USA, about 1,300 observations) from January 2, 1930 through December 30, 1962, NIKKEI (Japan, about 650 observations) from January 5, 1970 through April 30, 1983, TSX (Canada, about 400 observations) from January 2, 1976 through November 30, 1983, Statex Actuaries Index (Australia, about 550 observations) from March 1, 1973 through November 30, 1982, and Financial Times Ordinary Share Index (United Kingdom, about 1,600 observations) from January 2, 1950 through November 30, 1983.

Having analyzed the data sets, I found that return on Monday seriously depended on that registered the previous week. Return on stocks in each analyzable period is higher on Monday on average (about 0.08), if 
the index behaved positively the previous week and vice versa (on average -0.22 , with some distinctions in the United Kingdom). The authors explain such distinctions of the Monday effect as follows.

1. First of all, the correlation may be deceitful, with its higher value arising from autocorellation and aggregated data used for analysis purposes, rather than individual transactions. To verify the statement, the authors corroborated the significance of relationship between return on Monday after the market grows and before the market falls. It debunked the assumption about a false correlation.

2. Another explanation refers to an increase in the risk (associated with return) on Monday after the market growth the previous week and some decline in case of the market slowdown the previous week. However, this reason does not correspond with estimated standard deviation as a risk metric. In each of the analyzable countries, standard deviation of return on Monday is higher after the stock market fall the previous week than after its growth.

3. Similar effect exists throughout the whole week. The authors verified this explanation by constructing a regression model, where return on a particular day is a dependent variable of return recorded for the previous week. As a result, the model appeared to be meaningful for four of the five countries (by $t$ test) on with respect to Monday.

In 2001, J.M. Steeley [12] released his research on the United Kingdom, where he mentioned that the endof-the-week effect disappeared in the UK markets in the 1990s. The research analyzes FTSE100 by daily records from April 3, 1991 through May 19, 1998 (about 1,800 observations). Whereas inputs do not report on any substantial difference between yields by day of the week, these authors and their followers examine negative sets of yields by day. As a result, in addition to the above observation, they traced a statistically significant return not only on Monday, but also on Friday (-0.0068) in comparison with the middle of the week (average -0.0053). Indeed, they did not detect any considerable day-specific changes in case of positive return.

To elucidate the observations, I analyzed trends reflecting how the British stock market learns about macroeconomic developments. This information appears to come mainly from Tuesday through Thursday, while Monday and Friday are much less informative. In this respect, it is possible to conclude that the absence of news during those days brings the return to lower levels since brokers are generally inclined to buy. It is primarily Monday when they lure investors to sell. This explanation is quite reasonable upon the whole.

Furthermore, in 2001, S. Mehdian and M.J. Perry presented their work on the Monday effect in the U.S. stock market within 1964-1999. The study drew upon daily records on the closing of market trade with respect to five principal indices of large corporations in the U.S. stock market: Dow Jones Composite Average (DJCOMP), New York Stock Exchange index (NYSE), S\&P500, stocks of smaller companies (small caps' stocks), i.e. National Association of Securities Dealers Automated Quotation (NASDAQ) and Russell 2000 (RUSSELL). The sample period lasts from June 4, 1964 through February 6, 1998 and comprises 8,301 daily observations, except for RUSSELL, which is counted starting from January 2, 1979.

This research points out that during the period up to 1987 return on Monday was considerably negative for all the five U.S. stock indices analyzed herein (NYSE, S\&P500, DJCOMP, NASDAQ, RUSSELL). It corroborates conclusions of the previous researches. In case of the period after 1987, the Monday effect was found to be distorted in relation to high caps' indices, i.e. higher return on Monday. Moreover, the U.S. stock indices of high caps (NYSE, S\&P500, DJCOMP) and small caps (NASDAQ, RUSSELL) were considerably different in terms of the Monday effect.

The main conclusion is that the Monday effect is unstable, changing over time. Many empirical studies for the period of the complete samples within 1964 through 1998 and 1964 through 1987 proved to be true. These are:

- return on Monday is negative or much lower than return during the rest of the week (average -0.06 and -0.11 for respective periods);

- return on Monday has a positive correlation with the return of the previous week;

- negative Monday effect is mainly observed during the last two weeks of a month. 
In the mean time, the following observations of the period after 1987 were made:

- on Monday three high caps' indices generate positive return (about 0.09), with negative or insignificant return being derived from indices that mainly pertain to small caps (about - 0.03);

- statistically meaningful differences of Monday return from DJCOMP, S\&P500 и NYSE and return for the rest of the week were not found. On the contrary, Monday return and return for the rest of the week are not that different in case of NASDAQ and RUSSEL (about 0.02), but statistically meaningful;

- Monday return does not correlate with return for the previous week in case of all the indices, except for NASDAQ and RUSSEL;

- positive Monday effect is registered in case of DJCOMP, S\&P500 and NYSE during the first three weeks of a month, while in case of NASDAQ and RUSSEL Monday return is negative during the last two weeks of a month, being significantly low in comparison with Monday during the first three weeks of a month.

The latter results generally validate the above conclusions made by A. Kamara stating that the Monday effect decreased considerably. It was also confirmed that the traditional Monday effect morphed in the U.S. stock markets in case of high caps. The detected difference between Mondays of the same month corresponds with the findings made by K. Wang, Y. Li, J. Erickson, et al. In 1997 [14], indicating that the calendar-based nature stems from the size (capitalization) of a company. Furthermore, the positive Monday effect in case of S\&P500, DJCOMP and NYSE may result from low market efficiency, that is not considered as an anomaly in the stock market since return on Monday is not much higher than the return of the rest of the week, without depending on the market situation.

\section{Monday Effect in the Russian Stock Market}

In 2004, M. Kurashinov [15] carried out a similar research into the Russian stock market referring to two national indices - RTS index and MICEX index. The RTS and MICEX indices were analyzed from August 1, 1998 through August 31, 2004, and July 1, 1999 through August 31, 2004. Friday is showed to be the most income generating day of the week (increment in RTS and MICEX indices is 0.35 and 0.3 respectively). In this respect the Russian stock market resembles most of the Western stock markets, but the average return is much lower than that on the other days of the week. Moreover, the Wednesday return is obviously lower than nil (average -0.27), while the return of the other days is positive. It allows to reveal the explicit form of the Wednesday effect, which has not been registered in the Western stock markets.

Thus, it is possible to conclude that more successful traders, who support the trend, capture their profit, while other actors worry about a possible loss of their current profit, thus closing their positions as soon as the trend rebound shows off. As a result, the market adapts.

In the research by M. Kantolinskii ${ }^{2}$ in 2010, the average daily return of RTS index (September 1, 1995 through April 28, 2007) and MICEX Index (September 22, 1997 through April 28, 2007) indices was analyzed to identify the day-of-the-week effect. The both indices were reviewed by day of the week, without reference to trading on Saturday and Sunday. Having checked the data, the author indicates that signs of the Wednesday effect are detected, considering a small percentage of explained variance, i.e. abnormally low return in the Russian stock market on Wednesday. RTS index demonstrates distinctly negative return on Wednesday ( -0.17 against 0.21$)$. The same situation was observed in case of MICEX Index (-0.12 against 0.24$)$.

As the author puts it, the anomaly exists due to the deferred Monday effect and Tuesday effect in developed markets and some of developing ones. This testifies that the behavior of the Russian stocks is of secondary nature with respect to foreign securities. Liquidity flows shape the price trends with a certain lag, while the market depends on the way foreign investors act.

Empirical studies does not describe the subsequent period of transactions in the Russian stock market. Moreover, the recent decade witnesses not only the merger of the two major national trading platforms -

\footnotetext{
${ }^{2}$ Kantolinskii M.I. [Anomalies in the Russian stock market]. Moskovskaya mezhdunarodnaya konferentsiya po issledovaniyu operatsii (ORM2010): materialy konferentsii [Proc. Int. Sci. Conf. Moscow International Conference on Operation Research 2010]. Moscow, MAKS Press Publ., 2010, pp. 488-490.
} 
the Moscow Exchange (MICEX) and Russian Trading System (RTS), but also a big impact the global financial crisis has on Russia. In my opinion, this provides the rationale for further researches into behavioral effects in the Russian stock market.

\section{Methods and Inputs of This Research}

The framework of this research includes data on daily values of MICEX Index at the end of the trading day as published on the MICEX website for the period from January 10, 2007 through January 26, 2018. MICEX Index is price-specific, composite, weighted by market capitalization. It covers 50 most marketable stocks belonging to the largest and rapidly growing issuers from Russia, economic activities of which relates to the fundamental economic sectors listed on the Moscow stock exchange. The list of issuers and their percentage in the index are revised on a quarterly basis. Fig. 1 shows how MICEX Index changes throughout the said period.

The $(r)$ index return on the current day is calculated through the following formula:

$$
r_{t}=\frac{M I C E X_{t}-M I C E X_{t-1}}{M I C E X_{t-1}} .
$$

There were 4 and 13 trading sessions on Sunday and Saturday respectively for the analyzable period. Respective data were rejected as insufficient to determine meaningful statistics. I determined whether days of the week differ significantly using conventional methods. Unfortunately, it is problematic to build a regression model (following the method proposed in [7]) to evaluate the share and significance of return of certain days in the total return for the week due to a small percentage of explained variance using the available data.

\section{Results and Discussions}

Table 1 presents the average return of the analyzable index by day of the week and main sampling parameters. Fig. 2 compares the average return by day of the week and the average return for the week.

As the analysis of the findings shows, the Wednesday effect, which was discovered by M. Kantolinskii and M. Kurashinov, persists in the Russian stock market even after the Moscow Exchange MICEX and Russian
Trading system RTS merged. If the earlier proceedings feature the Friday effect, i.e. abnormally high return on Friday, I reveal that high return has been registered on Monday for the recent decade. If the average value is analyzed by logarithmic scale, Tuesday will be a turning point for it to become negative. Relatively high return on Monday and relatively low return on Wednesday are recorded among only positive and only negative values, thus defying the explanation about a serial correlation (Table 1).

The market behaves this way due to its persistence, or memory [16]. The phenomenon of market memory was pioneered by B. Mandelbrot [17], who unraveled the persistence of market prices, that is the ability of a certain trend to persevere in the market for a period exceeding the process which engendered it.

As the analysis reveals, financial markets have a longstanding memory, which is embodied as persistence or anti-persistence of time series of prices. In case of an anti-persistent and stochastic process, after some variable grows (price is concerned in this case), it usually decreases, and increases in the opposite case.

Market persistence is mainly examined through R/S analysis (Rescaled range analysis), which was devised by the British hydrologist $H$. Hurst [18]. The Hurst exponent can be located within the section $[0,1]$ and calculated within the following range:

$-0 \leq H<0.5$ signifies heavy tails in the distribution of variables, anti-persistent series, i.e. negative correlation in return dynamics, pink noise with frequent changes in directions;

$-H=0.5$ signifies that return changes are incidental, dynamics of prices for financial assets exemplifies the Brownian motion. Time series are adequately distributed. There is no correlation between changes in the value of assets (memory), with the white noise being validated;

$-0.5<H \leq 1$ signifies that there are heavy tails in the distribution of variables, persistent series, i.e. a positive correlation in the way return changes, black noise as evidence of market trends.

To identify the persistence of the analyzable market, it is necessary to pay attention to the Hurst exponent assessed for the entire sample and by day of the week (Table 2). 
Analyzing Table 2, it is possible to observe that $H$ is somewhat higher than 0.5 (except for Thursday). It means that the market return trend is not random in this sense. The fact may be due to two reasons. First, market developments do not have an immediate impact on prices (explanation concerning the invalidity of the market efficiency hypothesis). Second, after a certain period of time ends, the developments have a lower impact on prices for financial assets. This is the case of the market memory, being a well-known behavioral phenomenon. The effect is believed to fade away by the end of a financial week, and the cycle recommences afterwards.

\section{Conclusion}

Having reviewed the main outcome of empirical researches analyzing calendar anomalies in stocks markets of developed countries and Russia, I conclude that the behavioral effect originates and develops (it is behavioral economics that allows for the most plausible explanations) in quite a different way in developed and developing markets, as well as in case of developed and developing trading practices. The chronological periods may be linked with the origination of professional participation in the stock market and subsequent predominance of a collective (institutional) investor (mutual trust, non-governmental pension funds, etc.). The collective investor is not an individual, thus behaving in a more balanced and deferred manner to respond to market development, while the professional broker (or other person), which represents it, protects someone else's emotionally charged interests, rather than the broker's own ones.

As for the findings of the empirical results of this research, it is fair to note that the Russian stock market resembles those in most of developed countries in terms of the extent to which the day-of-the-week effect is apparent, and other behavioral distinctions. However, it lacks a consolidated source of macroeconomic information. Moreover, the Russian stock market is exposed to persistence effects emerging from relationships with other financial centers and economic cycles as whole. In my opinion, this is the reason why the Monday and Friday effects morph into the Monday and Wednesday ones, respectively, in Russia. All in all, further researches should be undertaken to clarify whether and how behavioral effects should be used to articulate an investment strategy.

Table 1

Average values of return by day of the week

\begin{tabular}{lllllll}
\hline Metric & Monday & Tuesday & Wednesday & Thursday & Friday & All days \\
\hline Average return & 0.002909 & 0.000011 & -0.000273 & 0.000221 & 0.000483 & 0.000646 \\
\hline Standard deviation & 0.063415 & 0.038152 & 0.020651 & 0.020964 & 0.021222 & 0.036445 \\
\hline Number of observations & 506 & 532 & 534 & 539 & 533 & 2,644 \\
\hline Positive values & & & & & \\
\hline Average return & 0.018397 & 0.015133 & 0.012093 & 0.013764 & 0.012353 & 0.014344 \\
\hline Standard deviation & 0.082915 & 0.029209 & 0.013953 & 0.017768 & 0.019934 & 0.041439 \\
\hline Number of observations & 264 & 273 & 266 & 261 & 269 & 1,333 \\
\hline Negative values & & & & & -0.011612 & -0.013281 \\
\hline Average return & -0.013987 & -0.015928 & -0.012547 & -0.012494 & 0.014669 & 0.023425 \\
\hline Standard deviation & 0.019366 & 0.039992 & 0.018828 & 0.014908 & 0.0143 \\
\hline Number of observations & 242 & 259 & 268 & 278 & 264 & 1,311 \\
\hline
\end{tabular}

Source:Authoring

\section{Table 2}

The Hurst exponent for return by day of the week

\begin{tabular}{lllllll}
\hline Metric & Monday & Tuesday & Wednesday & Thursday & Friday & All days \\
\hline The Hurst exponent $(\mathrm{H})$ & 0.574 & 0.5549 & 0.5023 & 0.4699 & 0.5383 & 0.5486 \\
\hline
\end{tabular}

Source:Authoring

Please cite this article as: Val'ko D.V. Calendar Anomalies in the Russian Stock Market: Trends of the Recent Decade. 
Figure 1

MICEX trends

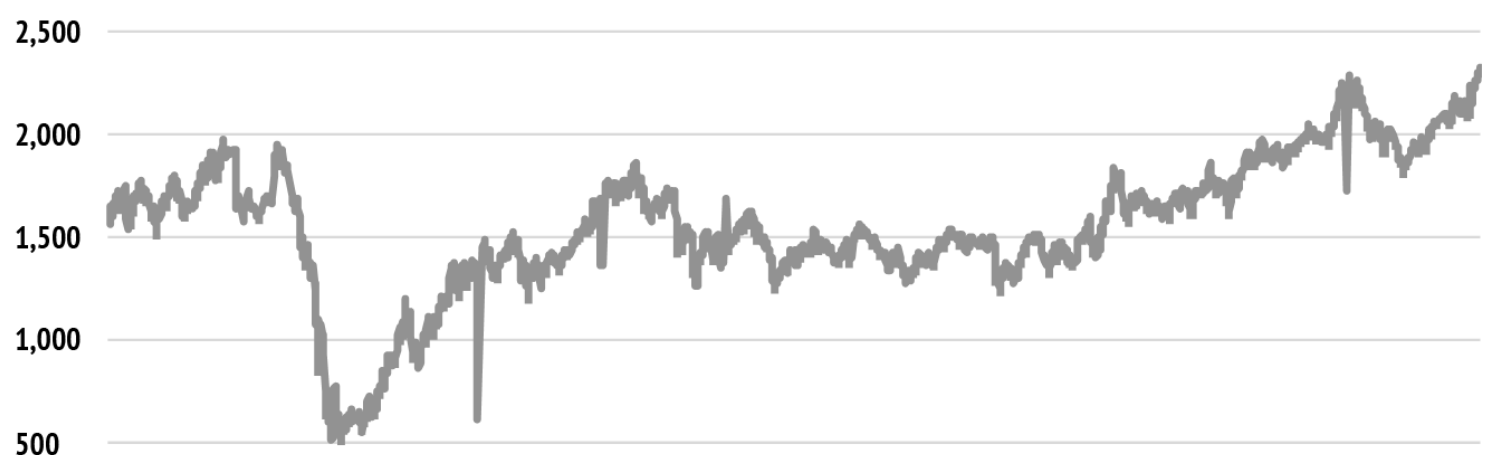

0

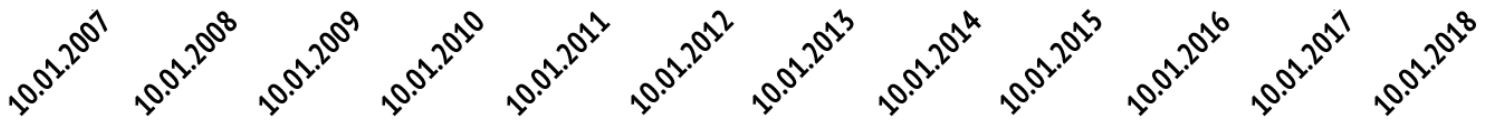

Source: Moscow Exchange

\section{Figure 2}

Comparison of average return by day of the week

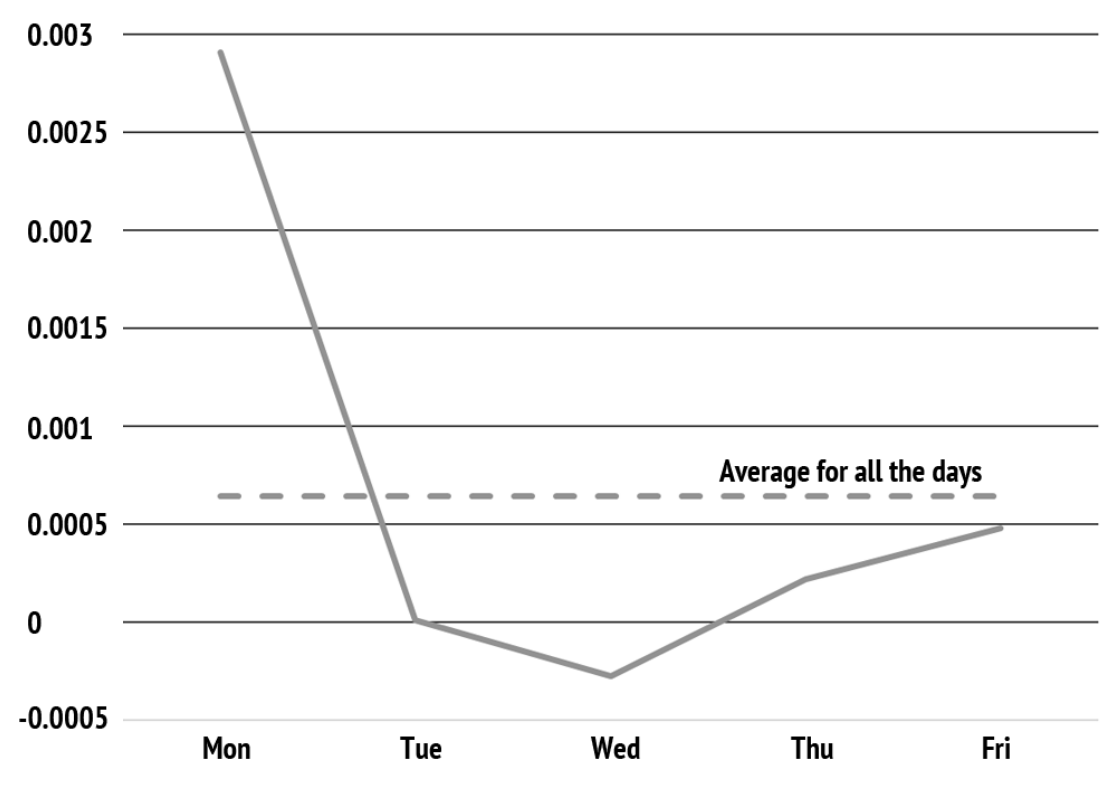

Source:Authoring 


\section{References}

1. Simon H. Administrative Behavior: A Study of Decision Making Processes in Administrative Organization. New York, Free Press, 1976, 400 p.

2. Harsanyi J.C., Selten R. A General Theory of Equilibrium Selection in Games. Cambridge, MA, MIT-Press, 1988, $378 \mathrm{p}$.

3. Tversky A., Kahneman D. Judgment under Uncertainty: Heuristics and Biases. Science, 1974, vol. 185, no. 4157, pp. 1124-1131.

4. Kantolinskii M.I. [Stock market anomalies: Definition and classification]. Vestnik Finansovoi akademii, 2010, no. 2, pp. 25-28. (In Russ.)

5. Fields M.J. Stock Prices: A Problem in Verification. Journal of Business, 1931, vol. 4, p. 415. URL: http://dx.doi.org/10.1086/232221

6. Cross F. The Behavior of Stock Prices on Fridays and Mondays. Financial Analysts Journal, 1973, vol. 29, no. 6, pp. 67-69.

7. French K. Stock Returns and the Weekend Effect. Journal of Financial Economics, 1980, vol. 8, iss. 1, pp. 55-69.

8. Lakonishok J., Smidt S. Are Seasonal Anomalies Real? A Ninety Year Perspective. Review of Financial Studies, 1988, vol. 1, no. 4, pp. 403-425.

9. Kamara A. New Evidence on the Monday Seasonal in Stock Returns. The Journal of Business, 1997, vol. 70, no. 1, pp. 63-84.

10. Agrawal A., Tandon K. Anomalies or Illusions? Evidence from Stock Markets in Eighteen Countries. Journal of International Money and Finance, 1994, vol. 13, iss. 1, pp. 83-106.

11. Jaffe J.F., Westerfield R., Ma C. A Twist on the Monday Effect in Stock Prices: Evidence from the U.S. and Foreign Stock Markets. Journal of Banking \& Finance, 1989, vol. 13, iss. 4-5, pp. 641-650.

12. Steeley J.M. A Note on Information Seasonality and the Disappearance of the Weekend Effect in the UK Stock Market. Journal of Banking and Finance, 2001, vol. 25, iss. 10, pp. 1941-1956. URL: https://doi.org/10.1016/S0378-4266(00)00167-9

13. Mehdian S., Perry M.J. The Reversal of the Monday Effect: New Evidence from US Equity Markets. Journal of Business Finance \& Accounting, 2001, vol. 28, iss. 7-8, pp. 1043-1065.

14. Wang K., Li Y., Erickson J. A New Look at the Monday Effect. The Journal of Finance, 1997, vol. 52, no. 5, pp. 2171-2186.

15. Kurashinov M. [The environmental effect, or the national trait of the Russian securities market]. Rynok tsennykh bumag = Securities Market, 2004, no. 20, pp. 13-15. (In Russ.)

16. Nekrasova I.V. [The Hurst index as a measure for the fractal structure and long-term memory of financial markets]. Mezhdunarodnyi nauchno-issledovatel'skii zhurnal = International Research Journal, 2015, no. 7-3, pp. 87-91. (In Russ.)

17. Mandelbrot B.B., Van Ness J.W. Fractional Brownian Motion, Fractional Noises and Applications. SIAM Review, 1968, vol. 10, no. 4, pp. 422-437. URL: https://doi.org/10.1137/1010093 
18. Hurst H.E. Long-term Storage of Reservoirs: An Experimental Study. Transactions of the American Society of Civil Engineers, 1951, vol. 116, iss. 1, pp. 770-799.

\section{Conflict-of-interest notification}

I, the author of this article, bindingly and explicitly declare of the partial and total lack of actual or potential conflict of interest with any other third party whatsoever, which may arise as a result of the publication of this article. This statement relates to the study, data collection and interpretation, writing and preparation of the article, and the decision to submit the manuscript for publication. 